\title{
Emerging innovation patterns in digital agriculture: A study of 198 digital solutions from 116 startups
}

\author{
Julian Schirmer \\ Montpellier Research in \\ Management \\ Montpellier University \\ France \\ julian.schirmer@, \\ etu.umontpellier.fr
}

\author{
René Eber \\ Montpellier Research in \\ Management \\ Montpellier University \\ France \\ rene.eber@ \\ etu.umontpellier.fr
}

\author{
Mauro Florez \\ Montpellier Research in \\ Management \\ Montpellier University \\ France \\ mauro.florez@ \\ umontpellier.fr
}

\author{
Isabelle Bourdon \\ Montpellier Research in \\ Management \\ Montpellier University \\ France \\ isabelle.bourdon@ \\ umontpellier.fr
}

\begin{abstract}
To tackle humanity's food challenges, agricultural companies need to exploit technological advancements by innovating their business models. Solution business model patterns (SBMPs) play a central role in business model innovation. However, the current literature on SBMPs is outdated and has not been adapted for the field of agriculture. By analyzing 198 digital solutions from 116 agriculture startups, we identify 18 SBMPs, nine of which have not been identified in any previous research. We thus significantly expand the existing literature on SBMPs and outline the technological drivers of emerging SBMPs. Furthermore, putting the 18 identified SBMPs into the context of agriculture will help agricultural companies innovate their business models. Three SBMPs with high potential to tackle humanity's food challenges are further discussed.
\end{abstract}

\section{Introduction}

Achieving the United Nations' zero hunger Sustainable Development Goal is a challenging endeavor. It is expected that global food demand will increase by $50 \%$ over the next three decades, without the ability to expand agricultural land, there is a high pressure to create innovative solutions [1]. Digital technologies play a major role in meeting this challenge, as they have the potential to significantly increase agricultural productivity, better allocate resources, and reduce food waste [2]. However, research has shown that companies need to innovate their business models in order to take advantage of new technologies [3]. The information systems (IS) community is well positioned to support agriculture organizations in their innovation journeys, as research on technology-driven business model innovation has been growing in importance in our field for more than
10 years [4]. One important field within business model innovation is solution business model patterns (SBMPs). SBMPs are abstract business model solutions to recurring problems. Collections of SBMPs play a central role in business model innovation, as $90 \%$ of all business model innovations are a recombination of existing SBMPs [5]. SBMPs help practitioners by addressing efficiency, spurring creativity, and helping overcome cognitive barriers in the business model innovation process [6]. However, the existing literature on SBMPs has two main shortcomings. First, Remane et al. [7] (to our knowledge, the most comprehensive literature review on SBMPs) did not identify any original source of SBMPs created after 2014. Therefore, they called for further research to identify new digital SBMPs. Second, researchers to date have not identified SBMPs specific to the agriculture industry. Thus, this paper focuses on identifying SBMPs emerging from digital agriculture startups. We study startups because, unlike traditional businesses, they tend to focus on a single business model [8], which facilitates the identification of new SBMPs. Our contributions are in two directions. On the one hand, as members of the IS community, we aim to provide the field of agriculture with a collection of agriculture-specific SBMPs, thereby helping agricultural organizations innovate their business models. Furthermore, we intend to offer scholars a solid understanding of emerging digital innovations from startups in agriculture. Both aspects foster innovation within the field of agriculture, which is necessary to tackle humanity's food challenges. On the other hand, as members of the IS community, we also want to learn from the field of agriculture. Amshoff et al. [9] argue that new SBMPs can be identified by studying how technologies are leveraged in industries and by deriving SBMPs at a level of generalization that allows them to be made applicable to other industries. The domain of digital agriculture is 
perceived as a highly innovative industry [10]. By studying SBMPs emerging from digital agriculture startups, we aim to complement the database of SBMPs compiled by Remane et al. [7] with new SBMPs. This paper is structured as follows. First, we define the concept of digital agriculture and SBMPs and outline the existing literature. Second, we describe our research design, which derives SBMPs from startups in digital agriculture. We then present the identified SBMPs and relate them to the existing SBMPs in Remane et al.'s database [7]. Finally, we discuss our findings and provide a conclusion.

\section{Definitions and existing literature}

\subsection{Definition of digital agriculture}

First, we look separately at the definitions of "digital" and "agriculture." Agriculture is known as both the science (scientific principles) and art (knowledge) of cultivating soil, including gathering crops and rearing livestock [11]. Thus, agriculture includes farming both plants and animals [12]. Digitalization refers to the use of digital technology, and often digitized information, to create and harvest value in new ways [13]. Digitalization in agriculture is considered the socio-technical process of applying digital innovations [14]. Such a process involves the development, adoption, and iteration of digital technologies in this sector, taking into account onfarm and off-farm tasks [14]. Digitalization in agriculture has been described using different terms, such as smart farming, digital agriculture, and Agriculture 4.0. Some of the current digital technologies used in agriculture include the Internet of Things (IoT), big data, artificial intelligence, cloud computing, remote sensing, and machine learning. The introduction of these technologies can significantly enhance the efficiency of agricultural activities by increasing productivity, improving allocation of natural resources, adapting to climate change, and reducing food waste [2].

\subsection{Definition of solution business model patterns (SBMPs)}

The concept of business model patterns has been studied intensively in the field of business model innovation. We derive the following characteristics of solution business model patterns from literature:

- Describe a "solution" to a recurring "problem" that needs to be solved [15].

- Describe "the core of the solution," often a solution for only a part of a business model [16].
Complete business models are thus often a combination of several patterns [17].

- Are usable "a million times over" and therefore require a certain level of generalization [9]. Furthermore, business model patterns can be classified into two different categories [9 p. $5 \mathrm{f}$ ]:

- $\quad$ Prototypical business model patterns are "holistic business models [describing] homogenous groups of companies. [They] permit a quick orientation when entering a new market but are not appropriate for developing new business models."

- Solution business model patterns (SBMPs) are building blocks for designing business models.

Thus, SBMPs and not prototypical business model patterns are leveraged for business model innovation. To further illustrate how SBMPs are leveraged, we outline the often-cited SBMP "razor/razorblade" as an example [5]. Companies offer a cheap basic product ("razors") with expensive complements that often need to be replaced ("blades"). The overpriced complements subsidize the basic product. This SBMP was originally derived from Gillette [5], but many companies have applied it. For example, Nespresso machines are sold cheaply, while the Nespresso capsules are comparatively expensive.

\subsection{Current literature on solution business model patterns (SBMPs)}

As mentioned in the introduction, Remane et al. [7] performed the most comprehensive literature review of SBMPs to date. However, they point out that no original research on SBMPs has been conducted since 2014 and call for further research to identify new digital business model patters. Amshoff et al. [9] argue that new SBMPs can be identified by studying how technologies are leveraged in certain industries and by deriving SBMPs at a level of generalization that allows them to be applied to other industries. Following Remane et al.'s call for research [7], several researchers have identified SBMPs by studying technologies in specific contexts. For example, Schüritz et al. [18] identified seven SBMPs - five of which were new to the database provided by Remane et al. [7] - by studying data-driven services. So far, to the best of our knowledge, no research has yet identified SBMPs in the field of digital agriculture. The only prototypical business model patterns in digital agriculture were identified by Kampker et al. [19], who explored business model patterns for industrial smart services. Given this review of the literature, we aim to identify emerging SBMPs in digital agriculture from startups using the methodology outlined in the following chapter. 


\section{Methodology}

Research designs differ for prototypical and for solution business model patterns. For prototypical business model patterns, the widely accepted methodological approach is to first create a business model pattern taxonomy and then derive patterns based on similar configurations within the taxonomy (see [20]). For SBMPs, researchers have adopted slightly different research designs (see $[9,18])$, which can be summarized as having three phases: data collection, codification of companies, and pattern identification. The following describes the adaptation of these three phases to our research scope.

\subsection{Phase 1: Data collection}

First, we identified the companies we intended to study and on which we planned to collect data. To ensure systematicity, we used the PRISMA (Preferred Reporting Items for Systematic reviews and MetaAnalyses) approach [21], shown in Fig. 1.

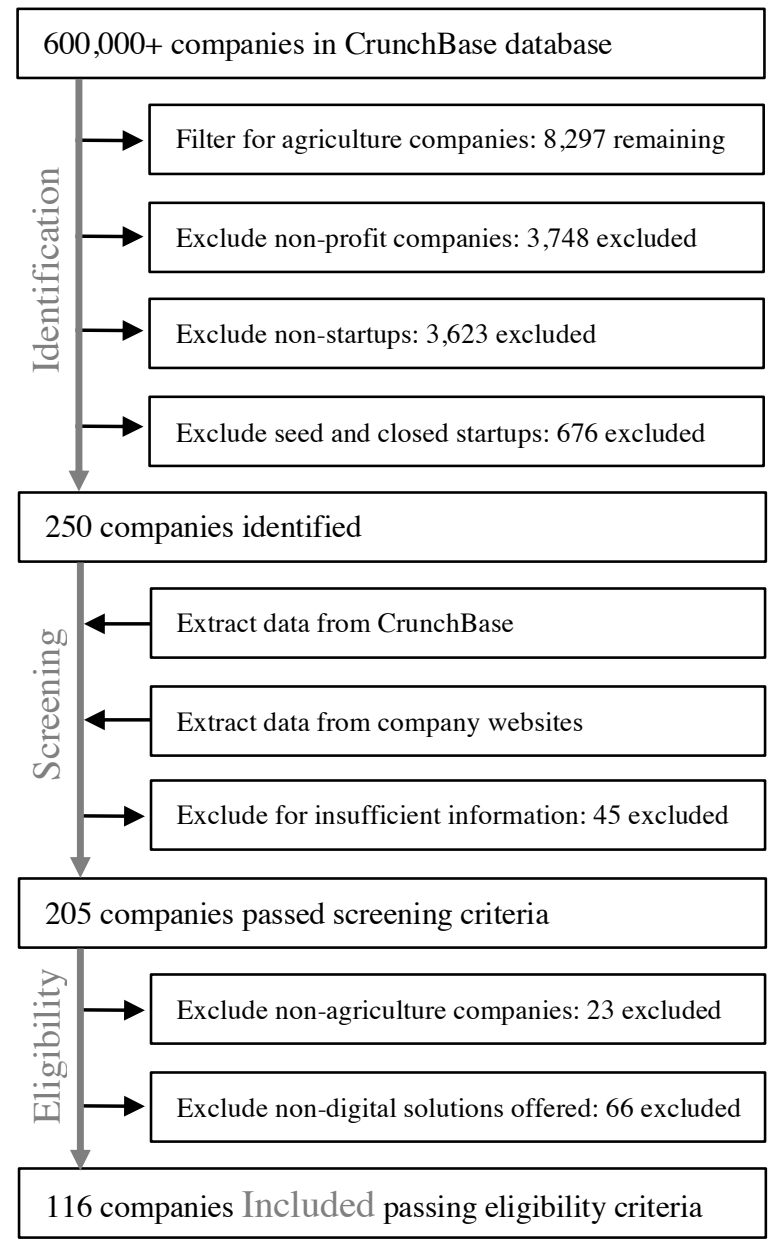

Figure 1 (2/2): Data collection process
The application of the four PRISMA steps is described below.

Identification: We decided to leverage a startup database, as Schüritz et al. did in [18]. However, instead of the startup database AngelList, which Schüritz et al. selected [18], we chose the startup database CrunchBase, as it is the world's most comprehensive database for high-technology startups and was thus better suited to finding digital agriculture startups. CrunchBase contains more than 600,000 company profiles and has over 55 million yearly users (crunchbase.com).

We selected the companies on March 29, 2020, and used several of CrunchBase's filter options. First, to focus on agriculture companies, we reviewed all category group filters and selected "Agriculture and Farming," resulting in 8,297 companies. Second, as our research focuses on business model innovation for profit maximizing companies, we excluded nonprofit organizations by filtering for the company type "for profit," excluding 3,748 companies. Third, to focus only on startups, we excluded based on the funding status filters "M\&A" (Merger \& Acquisition), "Private Equity," and "IPO" (Initial Public Offering), excluding 3,623 companies. Further, Hartmann et al. [20] stress that startups are prone to fail early. To reduce the risk of studying startups with unsuccessful business models, we decided to exclude startups with funding status "seed" as well as startups with operating status "closed," excluding 676 startups. We thus identified 250 startups.

Screening: Through CrunchBase, we extracted the following data, which we inserted into an Excel spreadsheet: name, full description, short description, categories, website address, and funding date. We also reviewed all startups' websites and extracted relevant information on their business model, which we added to the Excel spreadsheet. We excluded 45 startups, as they did not provide sufficient relevant information about their business model in their full description on CrunchBase or on their website.

Eligibility: We excluded 23 startups because they did not qualify as agriculture companies and 66 startups because no digital solution could be identified following the definition on page 2 .

Included: Ultimately, 116 startups qualified for our study. The average founding date of these startups was 2013, with the oldest startup founded in 1997 and the newest founded in 2018. Furthermore, the average amount of funding received per startup was 1,153,532 USD, with 636,334 USD as the lowest funding amount and $809,000,000$ USD as the highest funding amount. We thus believe that the selected startups on average have mature enough business models to identify SBMPs. 


\subsection{Phase 2: Codification of companies}

In the second phase, the startups were coded to facilitate pattern identification. Figure 2 below illustrates the codification process.

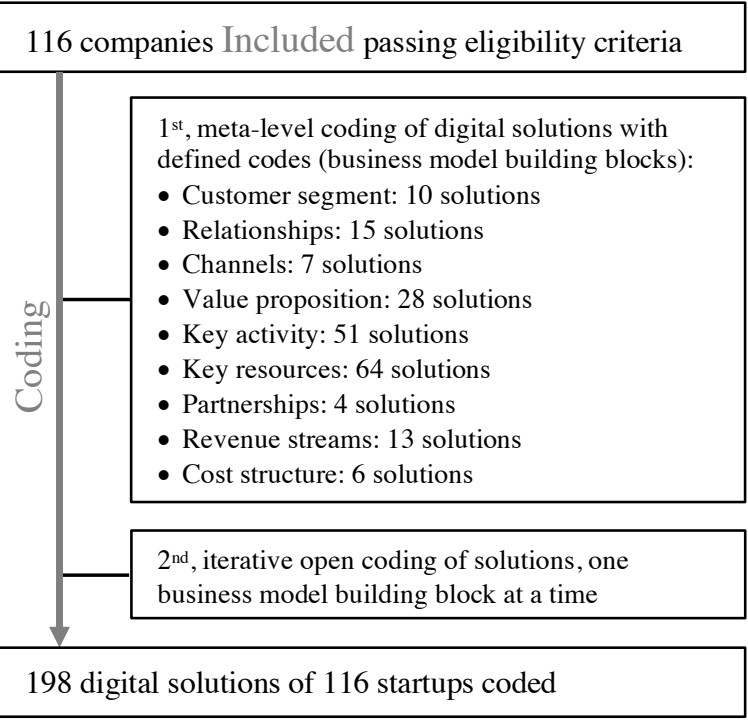

Figure 2: Codification of companies

Given the large set of 116 companies, we applied an approach similar to that of Remane et al. [22], who coded 487 companies in two steps. First, they applied meta-level coding to cluster the companies. Second, they separately analyzed each cluster for more efficient pattern identification. For the first step of meta-level codification, Amshoff et al. [9] stress the importance of an overall framework to cluster SBMPs along affected business model building blocks (referred to below as "blocks"). For our research, we chose the business model framework set forth by Osterwalder and Pigneur [17], as it is widely used in business model innovation research (cited by over 10,000 articles on Google Scholar as of November 25, 2019). As Amshoff et al. [9] point out, companies' business models consist of several SBMPs covering several "blocks." Therefore, startups whose full text description and website information covered more than one "block" were duplicated for each additional covered "block." This allowed us to code for several emerging SBMPs within each startup. From the full text description and websites of the 116 startups, 198 digital solutions were identified. Figure 2 shows the repartition of solutions into the different "blocks."

For the second coding within each affected block, more granular coding is needed. As the field of SBMPs in digital agriculture had not been explored before, we adopted "open coding" for theory development [23].
As the act of coding is affected by the subjectivity of the individual coder, we minimized this bias by performing all coding steps through two researchers independently. The codes were then reviewed; disputes were resolved in mutual discussion sessions and, when needed, a third reviewer was involved to resolve the dispute.

\subsection{Phase 3: Pattern identification}

In the third phase, the SBMPs were identified based on the codification of the solutions of the startups. The objective was to map the digital solutions of the startups onto SBMPs at an abstraction level similar to that of the SBMPs identified by Remane et al. [7] and to evaluate which converged with alreadyexisting SBMPs and which were new. Figure 3 illustrates the pattern identification process.

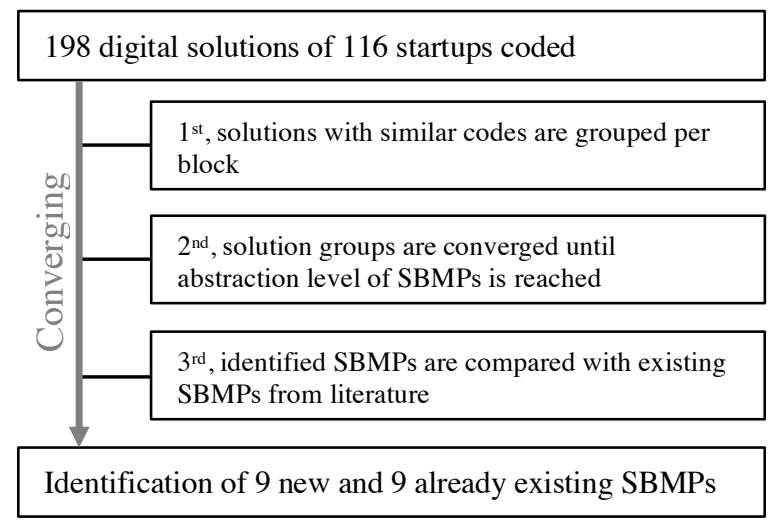

Figure 3: Pattern identification

The "blocks" proposed by Osterwalder and Pigneur [17] proved very useful, as each solution could clearly be allocated to one "block." To identify the SBMPs, we leveraged a three-step convergence approach.

First, within each "block," identical or very similar solutions were grouped based on their codes. Second, solution groups were converged until a abstraction level was reached similar to that of the SBMPs in Remane et al.'s literature review [7]. Several iterations and alignments between the researchers were needed. Finally, the identified SBMPs were compared to the 99 SBMPs identified by Remane et al. [7]. In total, we identified nine SBMPs that had already been described in the literature and nine new SBMPs. 


\section{Findings}

\begin{tabular}{|c|c|c|c|c|c|}
\hline Key Partners & Key Activities & \multicolumn{2}{|c|}{ Value Propositions } & Customer Relationships & Customer Segments \\
\hline \multirow[t]{3}{*}{ - Revenue sharing } & $\begin{array}{l}\text { - Enterprise resource } \\
\text { planning } \\
\text { - Smart process } \\
\text { automation } \\
\text { - Predictive risk } \\
\text { management } \# 51\end{array}$ & \multirow{3}{*}{\multicolumn{2}{|c|}{$\begin{array}{ll}\text { - Incomparable } \\
\text { offering } \\
\text { - Smart charged } \\
\text { products } \\
\text { - Smart business in a } \\
\text { box } \\
\text { - Sensor as a service }\end{array}$}} & $\begin{array}{l}\text { - Insights as points of } \\
\text { sale } \\
\text { - Transparency } \\
\text { branding } \\
\end{array}$ & \multirow[t]{4}{*}{ - Own the undesirable } \\
\hline & Key Resources & & & Channels & \\
\hline & $\begin{array}{l}\text { - Company } 360 \\
\text { - Ecosystem } \\
\text { Knowledge } \\
\text { Management } \\
\text { - Environment } 360\end{array}$ & & & - Direct to customer & \\
\hline Cost Structure & & & \multicolumn{2}{|c|}{ Revenue Streams } & \\
\hline - Rent instead of buy & & & \multicolumn{2}{|c|}{$\begin{array}{ll}\text { - } & \text { Freemium } \\
\text { - } & \text { Subscription }\end{array}$} & \\
\hline
\end{tabular}

\section{Figure 4: Identified SBMPs using Osterwalder and Pigneur's [17] business model canvas}

Our research allowed us to identify 18 SBMPs in digital agriculture based on the 198 digital solutions among the 116 studied startups. Figure 4 provides an overview of the identified SBMPs, of which nine have already been identified in the literature and nine are new. Figure 4 outlines several important aspects.

First, it makes it easy to understand which SBMPs apply to which business model "blocks." This is a valuable insight, as it is common practice in business model innovation workshops to seek inspiration for specific business model "blocks", since innovation mainly consists of the recombination of SBMPs and a company might only want to innovate parts of its business model. Obviously, the additional SBMPs already identified in the literature need to be considered in such workshops as well.

Second, Figure 4 indicates in bold and italic the new SBMPs and in which business model "block" they emerged. This represents an interesting insight for studying the innovative potential of digital solutions in agriculture.

Third, for each business model "block," the number of identified digital solutions is provided in the bottom right corner. This offers an additional perspective, adding to the number of SBMPs per business model "block" as well as the frequency of digital solutions.
To further explain the identified SBMPs, in the next two pages Table 1 describes SBMPs that have already been described in the literature and Table 2 describes new SBMPs. Both tables follow the same structure.

The first column defines the SBMP. For the SBMPs already described in the literature in Table 1, the definition from one author is used and the author is cited. However, different authors might define the same SBMP in slightly different ways. For further information on the SBMPs described by other authors, please consult Remane et al.'s systematic literature review [7]. For the new SBMPs described in Table 2, we have adapted the definitions to the style of existing SBMPs to facilitate integrability. The definitions in the first column enable the SBMPs to be applied regardless of industry.

The second column puts the SBMPs in the context of agriculture at an abstraction level that allows different players within agriculture to adopt the SBMPs, while remaining agriculture-specific enough to ease application.

The third column provides examples of startups leveraging the SBMPs and hyperlinks to the startups' websites. This makes the SBMPs more tangible and allows specific examples to be studied in more detail.

The fourth column specifies, for each SBMP, the number of digital solutions from the startups that have been identified and converged to the SBMP. 


\begin{tabular}{|c|c|c|c|}
\hline $\begin{array}{l}\text { Existing } \\
\text { SBMP }\end{array}$ & $\begin{array}{c}\text { Agriculture } \\
\text { context }\end{array}$ & $\begin{array}{l}\text { Startup } \\
\text { example }\end{array}$ & $\#$ \\
\hline $\begin{array}{l}\text { "Own the undesirable" }{ }^{[24]} \text { : } \\
\text { Seek to serve market segments } \\
\text { that were previously not } \\
\text { attractive. }\end{array}$ & $\begin{array}{l}\text { Using digital technologies to serve especially } \\
\text { small farmers and consumers, who seem to be } \\
\text { unattractive segments due to their remote } \\
\text { location, language barriers, low levels of } \\
\text { digitalization or missing economies of scale. }\end{array}$ & $\begin{array}{l}\text { Wefarm.co allows farmers to ask } \\
\text { questions in their native language to } \\
\text { other farmers via SMS, leveraging AI } \\
\text { for translation and identifying suitable } \\
\text { farmers worldwide to respond. }\end{array}$ & 10 \\
\hline $\begin{array}{l}\text { "Direct to customer" }{ }^{[25]} \text { : } \\
\text { Deliver a product or service that } \\
\text { has traditionally gone through an } \\
\text { intermediary directly to the } \\
\text { customer. }\end{array}$ & $\begin{array}{l}\text { Enabling consumers to directly buy from farmers } \\
\text { through real-time farm inventory visibility, } \\
\text { optimized doorstep delivery, automated ordering } \\
\text { processes, and online presence for even "non- } \\
\text { digital" farmers. }\end{array}$ & $\begin{array}{l}\text { Laruchequiditoui.fr is an e-commerce } \\
\text { platform where users can form groups } \\
\text { to buy directly from local farmers. }\end{array}$ & 7 \\
\hline $\begin{array}{l}\text { "Incomparable offering" [26]: } \\
\text { Use R\&D skills to develop and } \\
\text { exploit proprietary technology to } \\
\text { offer unique products that } \\
\text { command high margins. }\end{array}$ & $\begin{array}{l}\text { Leveraging digital tools, especially machine } \\
\text { learning, in R\&D to develop crops, fertilizers, and } \\
\text { pesticides that are safer, greener, less risky, more } \\
\text { predictable, and/or likely to lead to higher } \\
\text { revenue. }\end{array}$ & $\begin{array}{l}\text { pivotbio.com leverages machine } \\
\text { learning to develop microbes able to } \\
\text { convert nitrogen from the air to } \\
\text { replace fertilizers. }\end{array}$ & 8 \\
\hline $\begin{array}{l}\text { "Sensor as a service" }{ }^{[27]} \text { : } \\
\text { Collect, process, and sell sensor } \\
\text { data for a fee. }\end{array}$ & $\begin{array}{l}\text { Acquiring agriculture-relevant data through soil } \\
\text { sensing, machinery data extraction, aerial } \\
\text { imagery, and in-plant sensors for specific } \\
\text { purposes or simply to sell. }\end{array}$ & $\begin{array}{l}\text { Greensightag.com offers aerial image } \\
\text { capture services through drones, } \\
\text { capturing five times the data of } \\
\text { typical cameras, including (e.g.) } \\
\text { thermal imaging. }\end{array}$ & 16 \\
\hline $\begin{array}{l}\text { "Enterprise resource planning" } \\
\frac{[25]:}{} \\
\text { Use an integrated back office } \\
\text { system to optimize business } \\
\text { processes and thereby reduce } \\
\text { costs. }\end{array}$ & $\begin{array}{l}\text { Using digital platforms as single point of access } \\
\text { for all available data to manage processes, assign } \\
\text { tasks, and share information to improve } \\
\text { production, management, financials, and } \\
\text { compliance. }\end{array}$ & $\begin{array}{l}\text { FarmiIQ.co is a map-based farm } \\
\text { management software that simplifies } \\
\text { communication, supports compliance, } \\
\text { and gives the same information to all } \\
\text { workers. }\end{array}$ & 16 \\
\hline $\begin{array}{l}\text { "Revenue sharing" } \\
\text { Share revenues with other } \\
\text { companies in order to create a } \\
\text { symbiotic relationship. }\end{array}$ & $\begin{array}{l}\text { Establishing symbiotic relationships between } \\
\text { different layers of integrated agriculture value } \\
\text { chains through revenue sharing from the farmer } \\
\text { up to the retailer. }\end{array}$ & $\begin{array}{l}\text { lawrencedale.com is a foundation } \\
\text { promoting community farming and } \\
\text { value chain collaboration, } \\
\text { significantly reducing waste, and } \\
\text { sharing benefits with farmers. }\end{array}$ & 4 \\
\hline $\begin{array}{l}\text { Continuously provide customers } \\
\text { with products or services and } \\
\text { regularly charge upfront fees. }\end{array}$ & $\begin{array}{l}\text { Ensuring regular revenue through subscription } \\
\text { models for automated grocery delivery, recurring } \\
\text { agriculture services, and access to data/insights. }\end{array}$ & $\begin{array}{l}\text { Terravion.com offers subscriptions to } \\
\text { regular aerial images of fields } \\
\text { obtained via flights using advanced } \\
\text { cameras. }\end{array}$ & 10 \\
\hline $\begin{array}{l}\text { "Freemium" }[5] \text { : } \\
\text { Offer basic services for free, } \\
\text { while charging a premium for } \\
\text { advanced or special features. }\end{array}$ & $\begin{array}{l}\text { Offering basic digital services and giving } \\
\text { customers the option to upgrade to more } \\
\text { advanced functionalities, such as farm analytics. }\end{array}$ & $\begin{array}{l}\text { Xfarm.ag offers a free app for } \\
\text { agriculture with advanced premium } \\
\text { functionalities such as yield forecasts. }\end{array}$ & 3 \\
\hline $\begin{array}{l}\text { "Rent instead of buy" }{ }^{[24]}: \\
\text { Temporarily lend a product to the } \\
\text { customer and charge rent. }\end{array}$ & $\begin{array}{l}\text { Renting advanced robots to replace costly } \\
\text { machinery and/or staff for specific occasions. }\end{array}$ & $\begin{array}{l}\text { Abundantrobotics.com rents robots } \\
\text { for automated apple harvests to allow } \\
\text { even smaller farmers to benefit from } \\
\text { automation. }\end{array}$ & 6 \\
\hline
\end{tabular}

Table 1: Existing SBMPs identified 


\begin{tabular}{|c|c|c|c|}
\hline $\begin{array}{c}\text { New } \\
\text { SBMP }\end{array}$ & $\begin{array}{c}\text { Agriculture } \\
\text { context }\end{array}$ & $\begin{array}{l}\text { Startup } \\
\text { example }\end{array}$ & $\#$ \\
\hline $\begin{array}{l}\text { "Insights as points of sale": } \\
\text { Make insights derived using data } \\
\text { science become sites of digital sales } \\
\text { and marketing services. }\end{array}$ & $\begin{array}{l}\text { Offering advice to farmers to sell suitable } \\
\text { products, improve their productivity, or } \\
\text { create personalized shopping lists and } \\
\text { recipes for consumers through AI and } \\
\text { linking to e-commerce. }\end{array}$ & $\begin{array}{l}\text { Agrostar.in offers analytics-based } \\
\text { agronomy advice to farmers linked to } \\
\text { agri-products such as suitable } \\
\text { fertilizers. }\end{array}$ & 8 \\
\hline $\begin{array}{l}\text { "Transparency branding": } \\
\text { Offering transparency to the customer, } \\
\text { thus building brand value for an } \\
\text { offering that is part of a service. }\end{array}$ & $\begin{array}{l}\text { Advertising agriculture products through } \\
\text { offered visibility on quality, origins, created } \\
\text { waste, types of seeds, and food safety by } \\
\text { leveraging sensors and blockchain for } \\
\text { digital "certificates." }\end{array}$ & $\begin{array}{l}\text { Indigoag.com offers access to data } \\
\text { and crop verification to meet } \\
\text { consumer demands for high-quality, } \\
\text { sustainably grown food. }\end{array}$ & 7 \\
\hline $\begin{array}{l}\text { "Smart charged products": } \\
\text { Charge products with machine } \\
\text { learning-based services and value } \\
\text { propositions. }\end{array}$ & $\begin{array}{l}\text { Offering automated robots and drones for } \\
\text { all agriculture tasks (e.g., harvesting, bird } \\
\text { control), smart devices to guide animal } \\
\text { behavior, and smart micro-farms for private } \\
\text { customers. }\end{array}$ & $\begin{array}{l}\text { Halterhq.com uses smart collars to } \\
\text { guide cows via sound and vibrations } \\
\text { to automate herd movements and } \\
\text { establish virtual fences. }\end{array}$ & 12 \\
\hline \begin{tabular}{|l|} 
"Smart business in a box": \\
Offer a hardware/software package that \\
fully automates the key processes of a \\
business embedded in an ecosystem, \\
allowing even unqualified people to \\
instantly run their own business.
\end{tabular} & $\begin{array}{l}\text { Automating farming processes from seed to } \\
\text { ready-to eat with very few tasks performed } \\
\text { in a highly guided way by any unskilled } \\
\text { user and/or enabling distribution of sales } \\
\text { processes from farmer to consumer through } \\
\text { automated ordering and supply chain } \\
\text { processes. }\end{array}$ & $\begin{array}{l}\text { Nthing.net designs and engineers } \\
\text { containers with smart vertical farming } \\
\text { solutions, allowing anybody to be a } \\
\text { farmer. }\end{array}$ & 8 \\
\hline $\begin{array}{l}\text { "Smart process automation": } \\
\text { Enhance digitally equipped products } \\
\text { with machine learning capabilities to } \\
\text { automated processes. }\end{array}$ & $\begin{array}{l}\text { Leveraging sensors and machine learning to } \\
\text { optimally automate tasks such as precision } \\
\text { irrigation, spraying, and fertigation; } \\
\text { environment control in greenhouses and } \\
\text { cold rooms; and predictive maintenance. }\end{array}$ & $\begin{array}{l}\text { Ecorobotix.com leverages smart, } \\
\text { automated robots to detect and } \\
\text { selectively spray weeds using } 95 \% \\
\text { less herbicide. }\end{array}$ & 23 \\
\hline $\begin{array}{l}\text { "Predictive risk management": } \\
\text { Identify possible risks early through } \\
\text { data acquisition and data science to } \\
\text { proactively manage threats, reducing } \\
\text { the probability and/or severity of risk } \\
\text { occurrence. }\end{array}$ & $\begin{array}{l}\text { Detecting risks such as weeds, nutrient } \\
\text { deficiencies, pests, water damage, } \\
\text { machinery problems, crop growth deviation, } \\
\text { pollination, and animal health issues } \\
\text { through image recognition of fixed cameras } \\
\text { and drones and machine learning. }\end{array}$ & \begin{tabular}{|l|} 
Taranis.ag gains submillimeter- \\
resolution aerial imagery of crops \\
through drones, enabling the detection \\
of weeds, pests, and the like.
\end{tabular} & 12 \\
\hline $\begin{array}{l}\text { "Ecosystem knowledge management”: } \\
\text { Transform an ecosystem's data into } \\
\text { useful information and knowledge } \\
\text { which can then be stored. }\end{array}$ & $\begin{array}{l}\text { Gathering data horizontally across other } \\
\text { farmers and/or vertically across the value } \\
\text { chain to share best practices and } \\
\text { benchmarks on fields, crops, operators, } \\
\text { machinery, processes, and so on. }\end{array}$ & $\begin{array}{l}\text { Fbn.com is an independent network of } \\
\text { farmers that allows its members to } \\
\text { benchmark their field performances } \\
\text { against thousands of farmers and } \\
\text { create useful insights. }\end{array}$ & 4 \\
\hline $\begin{array}{l}\text { "Environment 360": } \\
\text { Gather information about important } \\
\text { aspects of the business environment to } \\
\text { predict information. }\end{array}$ & $\begin{array}{l}\text { Predicting changes and gathering } \\
\text { information on the agriculture business } \\
\text { environment, such as local weather, land } \\
\text { value, and commodity prices through data } \\
\text { acquisition and machine learning. }\end{array}$ & $\begin{array}{l}\text { Cibotechnologies.com predicts land } \\
\text { price dynamics parcel by parcel to } \\
\text { reduce costs of field acquisition. }\end{array}$ & 12 \\
\hline $\begin{array}{l}\text { "Company 360": } \\
\text { Gather information about important } \\
\text { aspects of the company (e.g., } \\
\text { processes, condition of resources) to } \\
\text { predict information. }\end{array}$ & $\begin{array}{l}\text { Changing predictions of and monitoring in } \\
\text { real time key company elements such as } \\
\text { yield, inventory, and herd movements } \\
\text { through data acquisition and machine } \\
\text { learning. }\end{array}$ & $\begin{array}{l}\text { agerpoint.com uses lidar to provide a } \\
\text { full inventory of all plants in fields } \\
\text { with geographical anchors. }\end{array}$ & 32 \\
\hline
\end{tabular}

Table 2: New SBMPs identified 


\section{Discussion}

Our analysis of 198 digital solutions from 116 startups in digital agriculture allowed us to identify 18 SBMPs.

Below, we first discuss our findings from an agriculture perspective and then from an IS perspective.

From an agriculture perspective, the selection of SBMPs with specific relevance for agriculture and their descriptions in context promote innovation potential in this field. However, some SBMPs have greater ability to tackle humanity's food challenges than others. We highlight three of the most promising SBMPs below.

First, the SBMP "smart business in a box" has the potential to tackle the issue of limited agricultural land by enabling urban farming; increasing the number of farmers by democratizing farming through allowing unqualified people to start farming; and reducing transportation distances of agriculture outputs through urban or local production. For example, the startup Nthing.net designs and engineers containers with smart vertical farming solutions, allowing anyone to become a farmer in urban areas.

Second, the adoption of the SBMP "predictive risk management" has the potential to increase global harvest yields. For example, the startup Taranis.ag obtains submillimeter-resolution aerial imagery of crops through drones, allowing farmers to identify, analyze, and treat early signs of crop threats - such as weeds, pests, and insects - to maximize yield.

Third, the SBMP "smart charged products" can significantly support farmers, thus increasing each farmer's efficiency. For example, the startup Halterhq.com uses smart collars to guide cows via sound and vibrations to automate herd movementsfor example, to maximize milk production through automated pasture allocation and cow health monitoring.

Promoting the innovative business models of agriculture companies through these SBMPs could offer significant help in tackling humanity's food challenges. Such promotions could include, for example, further research on how to best implement these SBMPs, financial aid to finance investments, or innovation coaching to enable agriculture companies to adapt the SBMPs to their specific circumstances.

From an IS perspective, much can be learned from the field of digital agriculture. Identifying nine new SBMPs in itself represents an important contribution, and it is interesting to discuss which drivers have led to the emergence of these new SBMPs. In the following section, we discuss the three most important drivers, in our opinion, and facilitate the understanding of the link between our findings in digital agriculture and IS, which we will extrapolate from the three already-discussed SBMPs.

First, a key driver for new SBMPs is the increasing importance of IoT devices. For example, the SBMP "smart business in a box" only becomes feasible when objects gather needed information and are connected to a broader community via the Internet to enable unqualified people to run the business. Another example is the SBMP "company 360," which provides company transparency through IoT devices. Considering that the number of IoT devices worldwide is expected to increase from 30.73 billion in 2020 to 75.44 billion in 2025 [28], we expect further SBMPs to emerge from the IoT trend.

Second, the increasing amounts of available data and advancements in data science serve as a key driver. For example, the SBMP "predictive risk management" is mainly built on analytics to anticipate risk. A SBMP that is applicable beyond agriculture will gain significant importance. Another example is the SBMP "ecosystem knowledge management," which is built on the sharing of increasingly valuable data in ecosystems. This driver will also gain importance, as it is estimated that the volume of data produced globally reached 12.5 zettabytes in 2014 and 50.5 zettabytes in 2020 and will reach 175 zettabytes in 2025 [29].

Third, automation is a key driver. For example, the SBMPs "smart charged products" and "smart process automation" leverage advancements in artificial intelligence and robotics to automate human tasks. Considering that, for example, $14 \%$ of jobs across the OECD (Organization for Economic Cooperation and Development) countries are at risk of full automation and $32 \%$ of jobs are likely to see significant changes, we expect significant changes in business models due to automation [30].

It is reasonable to assume that the identified technological drivers will lead to additional SBMPs that have not yet been identified. As members of the IS community, we can contribute to the identification of new, technologically driven SBMPs by further studying the innovation potential of the three drivers. 


\section{Conclusion}

To solve humanity's food challenges, it is crucial that we enable the field of agriculture to develop innovative business models to incorporate technological advancements. SBMPs play a crucial role in this process. However, the current literature has two shortcomings. First, the databank of SBMPs in the literature identified by Remane et al. [7] does not contain any original research on SBMPs after 2014; as such, SBMPs evolving from emerging technological trends in recent years are missing. Second, no research on SBMPs in the field of agriculture has been performed to date.

To address this research gap, we studied 198 digital solutions from 116 digital agriculture startups. This allowed us to identify 18 SBMPs, which we additionally described in their agricultural context. Compared to the SBMP database compiled by Remane et al. [7], we identified nine new SBMPs. Our contributions are in two directions.

First, the IS community can provide the agricultural community with a collection of SBMPs that are highly relevant to agriculture and can support efficient business model innovation in practice. We can also provide scholars in this field with a solid understanding of emerging innovation patterns in digital agriculture. This contribution aims to support the integration of technological advancements in the much-needed new business models to help tackle humanity's food challenges.

Second, the IS community can learn from the field of digital agriculture. Identifying nine new SBMPs that are applicable beyond agriculture in itself represents an important contribution, considering that Remane et al. [7] identified 99 SBMPs based on 19 research articles. The identification of nine additional SBMPs can be explained by the fact that Remane et al. did not identify any original source of SBMPs created after 2014 and because digital agriculture is a highly transformative and innovative industry sector [10]. Furthermore, the three discussed technological drivers for new SBMPs can help us, as a community, focus our research on more efficient technology-driven business model innovations.

Our study is not free from limitations. First, we limited the scope of this article to startups only. This represented a fruitful approach for identifying SBMPs, and the focus on startups in identifying novel phenomena is a widely used approach. However, additional SBMPs could be identified by also studying larger corporations.

Second, although the leveraged startup database CrunchBase is the most comprehensive database of high technology startups, its list of covered startups is not exhaustive (e.g., CrunchBase does not include Africa as a region filter). In addition, the tags we used to identify digital agriculture startups are selected by the companies themselves; therefore, we cannot guarantee that we identified all digital agriculture startups on CrunchBase. Therefore, future research should be conducted to identify SBMPs based on different objects of study, e.g. by leveraging other databases such as AngelList.

Third, we leveraged the descriptions of startups provided on CrunchBase and the information provided on the startups' websites. We thus studied the startups based on information that they themselves had selectively published. SBMPs that startups use but do not advertise therefore could not be identified. Additional research based on primary data thus has the potential to identify additional SBMPs.

Finally, we believe that the identified SBMPs can play a major role in improving performance in agriculture and thereby tackling humanity's food challenges. However, further research is needed to better understand how and which types of innovations within agriculture can contribute to tackling humanity's food challenges and to what degree.

\section{References}

[1] J. De Sá, F. Declercq, D. Maine, and F. Martins, "Conquering the Food Challenge Through Agriculture 3.0", Bain \& Company, São Paulo, Brazil, URL: https://www.bain.com/insights/conquering-the-foodchallenge-through-agriculture-3/, visited on 15/04/2020, 2017.

[2] Z. Zhai, J. F. Martínez, V. Beltran, N. L. Martínez, "Decision support systems for agriculture 4.0: Survey and challenges", Computers and Electronics in Agriculture 170 (1), 2020, pp. 105256.

[3] S. Slater, and J. Mohr, "Successful Development and Commercialization of Technological Innovation: Insights Based on Strategy Type", Journal of Product Innovation Management 23, 2006, pp. 26-33.

[4] M. M. Al-Debei, and D. Avison, "Developing a unified framework of the business model concept", European Journal of Information Systems 19 (3), 2010, pp. 359376.

[5] O. Gassmann, K. Frankenberger, and M. Csik, The business model navigator: 55 models that will revolutionise your business, Pearson, London, 2014.

[6] H. Chesbrough, "Business model innovation: opportunities and barriers.", Long range planning 43 (2), 2010, pp. 354-363.

[7] G. Remane, A. Hanelt, J. F. Tesch, and L. M. Kolbe, "The business model pattern database - a tool for systematic business model innovation", International Journal of Innovation Management 21(01), 2017, pp. 1750004 . 
[8] V. Sabatier, V. Mangematin, and T. Rousselle, „From recipe to dinner: business model portfolios in the European biopharmaceutical industry", Long Range Planning 43 (2), 2010, pp. 431-447.

[9] B. Amshoff, C. Dülme, J. Echterfeld, and J. Gausemeier, „Business model patterns for disruptive technologies." International Journal of Innovation Management 19 (03), 2015, pp. 1-22.

[10] C. R. Trendov, R. M. Cortina, and R. J. Said, "U.S. Patent No. 10,471,987", U.S. Patent and Trademark Office, Washington, DC, 2019.

[11] D. R. Harris, and D. Q. Fuller, "Agriculture: Definition and Overview." Encyclopedia of Global Archaeology 13 (1), 2014, pp. 104-113.

[12] P. Edwards, and H. Demaine, "Rural Aquaculture: Overview and Framework for Country Reviews", Bangkok, Thailand, 1998.

[13] M. M. Gobble, "Digitalization, Digitization, and Innovation", Research Technology Management 61 (4), 2018, pp. 56-59.

[14] L. Klerkx, E. Jakku, and P. Labarthe, "A review of social science on digital agriculture, smart farming and agriculture 4.0: New contributions and a future research agenda", NJAS - Wageningen Journal of Life Sciences 90-91 (11), 2019, pp. 100315.

[15] A.B. Abdelkafi, N. S. Makhotin, and T. Posselt, „Business model innovations for electric mobilitywhat can be learned from existing business model patterns?", International Journal of Innovation Management 17 (01), 2013, pp. 1-41.

[16] P. Weill, and M. Vitale "Place to space: Migrating to eBusiness Models", Harvard Business Press, Boston, 2001.

[17] A. Osterwalder, and Y. Pigneur, Business model generation: a handbook for visionaries, game changers, and challengers, John Wiley \& Sons, Hoboken, 2010.

[18] R. Schüritz, S. Seebacher, and R. Domer, ,Capturing Value form Data: Revenue Models for Data-Driven Services", Proceedings of the 50th Hawaii, 2017.

[19] A. Kampker, P. Jussen, and B. Moser, "Industrial smart services: types of smart service business models in the digitalized agriculture", International Conference on Industrial Engineering and Engineering Management (IEEM), 2018, pp. 1081-1085.

[20] P. M. Hartmann, M. Zaki, N. Feldmann, and A. Neely, "Capturing value from big data-a taxonomy of datadriven business models used by start-up firms", International Journal of Operations \& Production Management 36 (10), 2016, pp. 1382-1406.

[21] A. Liberati, D. G. Altman, J. Tetzlaff, C. Mulrow, P. C. Gøtzsche, J. P. Ioannidis, and D. Moher, "The PRISMA statement for reporting systematic reviews and metaanalyses of studies that evaluate health care interventions: explanation and elaboration", Journal of clinical epidemiology, 62(10), 2009, e1-e34.

[22] G. Remane, B. Hildebrandt, A. Hanelt and L. M. Kolbe, „Discovering New Digital Business Model Types-a Study of Technology Startups from the Mobility Sector", Proceedings of the 20th Pacific Asia Conference on Information Systems, Chiayi, Taiwan, 2016.
[23] J. M. Corbin, and A. Strauss, „Grounded theory research: Procedures, canons, and evaluative criteria", Qualitative sociology 13 (1), 1990, pp. 3-21.

[24] M. W. Johnson, "Business Model Analogies", URL: $\mathrm{http}: / /$ www.innosight.com/innovationresources/upload/STWS_Business_Model_Analogies. pdf, visited on 20/11/2019, 2009.

[25] J. Strauss, and R. Frost, "E-Marketing", 7th edn. Pearson Prentice Hall, Upper Saddle River, NJ, México, 2014.

[26] J. Linder, and S. Cantrell, "Changing Business Models: Surveying the Landscape", URL: http://course.shufe.edu.cn/jpkc/zhanlue/upfiles/edit/20 $1002 / 20100224120954 . p d f$, visited on $20 / 11 / 2019$, 2000.

[27] E. Fleisch, M. Weinberger, and F. Wortmann, 2015. "Business models and the internet of things", Interoperability and Open-Source Solutions for the Internet of Things, Springer, Cham, 2015, pp. 6-10.

[28] Statista, "Internet of Things (IoT) connected devices installed base worldwide from 2015 to 2025", URL: https://www.statista.com/statistics/471264/iot-numberof-connected-devices-worldwide/, visited on 03/05/2020, 2020.

[29] Statista, "Volume of data/information created worldwide from 2010 to 2025", URL: https:/www.statista.com/statistics/871513/worldwidedata-created/, visited on 03/05/2020, 2020.

[30] OECD, "Job automation risks vary widely across different regions within countries", URL: https://www.oecd.org/newsroom/job-automationrisks-vary-widely-across-different-regions-withincountries.htm, visited on 03/05/2020, 2020. 